\title{
Healing Strategies among Thai Buddhist Widows after Sudden of Loss of Spouse in Terrorist Attacks
}

\author{
Sujira WICHAIDIT ${ }^{1, *}$, Praneed SONGWATHANA ${ }^{1}$, \\ Karnsunaphat BALTHIP ${ }^{1}$ and Martin WOODS ${ }^{2}$ \\ ${ }^{1}$ Faculty of Nursing, Prince of Songkla University, Songkhla 90110, Thailand \\ ${ }^{2}$ Graduated School of Nursing, Victoria University of Wellington, Wellington, New Zealand
}

('Corresponding author's e-mail: sujira.w@psu.ac.th)

Received: 31 May 2017, Revised: 25 June 2018, Accepted: 19 July 2018

\begin{abstract}
Background: Both physical and psychological suffering among women after the loss of their husband as a result of traumatic events has been evident. However, little is known about the strategies used by Thai widows who are able to heal and return to normal living in areas of unrest.

Objectives: The purpose of this study is to describe the healing strategies used by Thai Buddhist widows to heal their suffering from the sudden loss of their spouse in terrorist attacks.

Methodology: This is a primary analysis of data generated from a qualitative study of Thai Buddhist widows who lost their spouse because of terrorist attacks in the southernmost provinces of Thailand. Five Buddhist widows were purposively selected to participate in the study, using in-depth interviews and observation for data collection. Content analysis was employed as part of the data analysis to identify and describe the strategies used by the selected participants.

Results: The participants were aged between 37 and 64 years old and had experienced the loss of a spouse within the previous 2 to 10 years. They had been successful in healing their suffering. Several strategies had been used, with initial support and assistance from families and close friends. Firstly, as per the Buddhist belief system, 'merit making', such as praying, practicing meditation, or offering money and/or food to monks, was often performed by the women. These practices helped them to ease their anxiety about their husbands' afterlife happiness and whether or not they were living in a good place. Secondly, venting their feelings and emotions with family and close friends, including talking to their husband's picture, provided some suffering relief. Lastly, a deep understanding of Dukkha (suffering) and the natural law of life in Buddhism helped widows to realize the right ways to create a positive mindset and new future life.

Conclusions/Recommendations: The strategies used to heal themselves from suffering by Thai Buddhist widows could be of benefit for nurses, to enable them to develop interventions that not only relieve human suffering from the unexpected loss of loved ones, but also promote mental health through healing and spiritual growth in their own lives.
\end{abstract}

Keywords: Buddhism, suffering, healing strategies, widow, psychological trauma

\section{Introduction}

Throughout the history of warfare and terrorism, armed conflict has been one of the major causes of death. Because of war and armed conflicts, the health of the public is greatly affected by physical injury, psychological trauma, decreased sanitation and hygiene, and deterioration of the health infrastructure [1]. Furthermore, exposure to loss of family members and significant others are important causes of human suffering $[2,3]$. 
http://wjst.wu.ac.th

Regarding the psychosocial effects of the victim's families, those deaths from manmade disasters caused more suffering than those from natural disasters [4]. Additionally, survivors who had lost someone from a violent death had more severe grief symptoms than those who had lost a significant other from a nonviolent death. Post-Traumatic Stress Disorder (PTSD) in particular was found to be the most significant psychological health condition after exposure to traumatic events and situations of unrest [5]. The effect could be reduced but remained in the long term, as a previous study showed that people who were directly exposed to traumatic events- especially terrorist events- presented with high PTSD, at a rate of $28.8 \%$ during the first month, but this decreased to $17 \%$ at 12 months [6]. These changes could be dynamic or lethargic, according to how people attribute meaning to their loss and the various responses and strategies used in healing themselves.

Over the past decades of the continuation of 'unrest situations' in the 3 southernmost provinces of Thailand, with a high number of deaths among the main breadwinners in many families, it is an example to learn for helping the widows and their families. This situation is worsening year by year, as a report by a local agency showed, with a dramatical increase in the number of widows from the unrest situations in southernmost Thailand between years 2012 and 2014, from 2,295 widows to more than 2,800 widows $[7,8]$. Although this number may be under-reported, many families are clearly experiencing frequent suffering and high psychosocial stress, particularly those families who lost their main source of income.

In Thai culture, Buddhism plays important role in helping them free themselves from suffering and guide their perceptions and living styles [9]. In addition, it is observed that an engagement in religious belief and practice was one of the most common healing methods used by most survivors to overcome the suffering [10,11]. However, self-healing is personal coping and may be different in each person or each group. Exploring self-healing in Thai Buddhist widows is then necessary for Thai society.

\section{Literature review}

Women who face terrorist attacks suffer a greater psychological impact than men, partly due to the loss of the leader of their family and of a loved one $[12,13]$. This is confirmed by the high number of Thai widows $(60 \%)$ who reported a high level of emotional stress and social stress in the first month after being exposed to a traumatic situation $[10,14]$. The sudden death of a spouse delivered several psychological impacts and economic impacts among widows, such as increase in stress and anxiety by uncertainty in their future due to the lessening of family income status [15]. Furthermore, loss of a spouse among young widows brought a higher degree of psychological depression, as was found, for instance, in unrest areas of Sri Lanka [16].

Due to the family role changes, most widows who became the family leader are exposed to many problems related to their greater responsibility for new household tasks. After loss of spouse, widows try to handle the traumatic emotional impacts. As a study in Sri Lanka showed, only $62 \%$ of the widows were able to stabilize their psychological equilibrium after 3 months of the death of their spouse [16]. In addition, various coping strategies were used, such as problem solving (58\%), or social support seeking $(24 \%)$, to overcome their suffering and undergo a state of healing for their well-being [15]. In a systematic review of the emotional state and self-management of widows, Holm and Severinsson [17] reported that widows healed their suffering by changing their perception and meaning of life under the theme of "a struggle to perceive meaning in the meaningless." This consisted of 3 sub-themes: 1) numbing and struggling to control feelings, 2) feeling sad and trying to maintain close emotional relationships and meaningful activities, and lastly, 3) the process of change and self-management, which were related to the human resilience.

Furthermore, a previous study described female experiences of the recovery process among Norwegian females suffering from a childhood trauma, who reflected their recovery process in 5 main themes, which consisted of 1) finding new ways to understand one's emotions and actions, 2) moving from numbness toward vital contact, 3) becoming an advocate of one's own needs, 4) experiencing increased sense of agency, and lastly, 5) staying with difficult feelings and choices [18]. So, the loss of a baby and loss of a beloved one should be different in the affected and healing strategies. 
http://wjst.wu.ac.th

Throughout sudden loss of spouse experiences, women who learned to heal themselves may encounter different outcomes. The success or failure of healing experiences may depend on several factors, such as the woman's background, social support, or beliefs. However, religious belief plays an important role, which influences a spiritual pathway to facilitate widows understanding and accepting the deaths of their spouses and helps them shape and transform their suffering until undergoing well-being through the healing process [19]. Religious belief also influences individual perception of the meaning of life and death after exposure to loss experiences, as well as understanding of the dying process. A study by Park [20] explored and described the religion as a meaning system and the role of religion in the coping process; the results indicated that there was an association between religion and the coping process by making meaning following loss. This is similar to Prati and Pietrantoni [21], who conducted a meta-analysis on factors associated with post-traumatic growth; it was found that religious coping and positive reappraisal coping were strongly correlated with growth. In addition, social support and spirituality caring were moderately related to positive changes.

In Buddhism in Thailand, as elsewhere, the relationship between religious belief and the healing experience is often found. As a study of Thai Buddhist mothers who had lost their child reported, there were 5 ways to heal suffering [22], which consisted of transforming their relationship with the deceased child, elevating the deceased child to be a very good child capable of going to heaven, making merit in order to pass the benefit on to the deceased child, self-healing through understanding and mind cultivation, and lastly, seeking support. They reflected healing strategies in 4 themes, which consisted of; being sufficiently alive, living for old karma, continuing to do more good deeds, and lastly, having a deeper understanding of life. Similar experiences were found in those who suffered by losing a loved one in Tsunami events; Buddhist belief influenced their meaning of suffering, under the belief of 'Law of nature' and 'Law of Karma' [11].

In Buddhism, 'suffering' is viewed as part of life, that 'being is suffering' [23]. Buddhism explains 'suffering' in a widening concept, consisting of 3 different aspects: 1) suffering in painfulness, which refers to suffering by nature, which can occur in anyone and consists of physical and psychological suffering; 2) suffering in change, which refers to suffering from changes such as loss or illness, and 3) suffering in formations, which refers to suffering from his or her own belonging and loss of belonging. Additionally, Buddhism teaching recommends that the way to lessen suffering (Dukkha) or become free from suffering is Magga [23,24].

'Magga' is the right way to end suffering, presented in the principle of Buddhism under the 3 dimensions of the 'Noble Eightfold Path' [23-25]. Buddhists who have the right understanding of 'Magga' would make merit and perform good deeds, avoid bad karma, and develop right thoughts. Secondly, morality (sila) or moral conduct consist of 3 aspects, such as right speech (samma vaca), right action (samma kammanta), and right livelihood (samma ajiva). Buddhists who have morality would respect truth, respect others, and lead to the development of a harmonious society. This helps people to respect personal relationships, to maintain love and trust and making a better society, and to live without violating the principle of moral conduct [23]. Lastly, concentration (samadhi); which consists of right effort (samma vayama), right mindfulness (samma sati), and right concentration (samma samadhi). These would enable people to strengthen and gain control over the mind and prepare to realize the truth in which to undergo freedom and receive "Enlightenment" [25]. Practicing the right effort can reduce and eliminate the number of unwholesome mental states and increase wholesome thoughts as a natural part of the mind. Right effort is closely associated with right mindfulness, which is one way to achieve the end of suffering, because of a full awareness of actions, feelings, and thoughts, after which the mind should always be clear. Right concentration is the practice of developing one-pointedness of the mind on one single subject [23].

Importantly, Buddhists who understand and realize the 'Noble Eightfold Path' will find it easier to move on when exposed to suffering (Dukkha) [26]. A study of Buddhist survivors who suffered from loss of a family member, socioeconomic collapse, and loss of occupation during a major tsunami revealed that Buddhist concepts had helped them shape the meaning of suffering [11]. Moreover, praying and meditation practice had influenced the mental processes and acts, and was also associated with healing suffering 
http://wjst.wu.ac.th

[27-29]. Ways of transforming from suffering to well-being are related to personal belief and religious belief, which are important factors in the healing process.

In the literature, a few studies have focused on the suffering and healing processes among Buddhist widows affected by terrorist attacks. With high levels of emotional stress and social stress, and moderate physical stress, among widows who were affected by unrest situations, most widows had struggled to overcome their suffering [14]. Yet these studies did not describe how religious belief systems influence coping and healing processes. The skills and specific interventions for healing the widows' suffering from traumatic events are also required [29]. In addition, the effectiveness of intervention in reducing anxiety or stress symptoms was in the short term and required more understanding of healing outcomes, such as resilience and spiritual growth [30]. Since the number of widows has been continuously increasing, it was observed that some women experienced success in returning to normal life [31]. However, it has been of less attention on how Thai Buddhist women heal themselves under the concept of healing and health in Buddhism, which is important for Thai Buddhists. This qualitative study is suggested to explore women's experiences in relation to healing from suffering, which could provide long term benefit to others.

\section{Study aim}

This study aims to describe the strategies used to heal the suffering of Thai Buddhist widows who experienced sudden loss of spouse from terrorist attack in the southernmost provinces of Thailand.

\section{Methodology}

Design

This descriptive qualitative study was employed to describe the healing strategies that Thai Buddhist widows used to heal their suffering after exposure to the sudden loss of a spouse. The study aimed to present a rich and comprehensive description of an experience from the participants' information. The descriptive qualitative study provided and facilitated researchers to generate findings closer to the raw data than other qualitative studies [32,33]. Lambert and Lambert [34] also stated that the qualitative approach is suitable and useful when the researcher needs to describe phenomena, particularly the specific events under study.

\section{Setting}

Pattani province was selected for the study's setting, as this province is the highest affected area, and has the highest number of widows, in comparison to the other provinces in southernmost Thailand affected by the unrest situations [7].

\section{Participants}

In the initial stage of data collection, the first 5 participants were selected from those who met the inclusion criteria. The inclusion criteria were for widows who 1) had been exposed to traumatic experiences from loss of spouse in terrorist attack situations at least 6 months previously, 2) had perceived themselves to be able to overcome the suffering and return to normal life or well-being, and 3) had no current psychological symptoms. The first participant was purposively selected from those who met the criteria introduced by a psychiatric nurse who takes responsibility in the area. Then, the snowball method was used to obtain a suitable sample of further participants. Data collection and analysis continued until no new information emerged or the data was saturated.

\section{Ethical considerations}

Research ethics approval was given by the Research Ethics Committee of the Faculty of Nursing, Prince of Songkla University (IRB number; PSU IRB 2017-NL007). All participants were informed about the purpose and benefits of study, and their right to refuse or withdraw based on the voluntary nature of their participation, before interview. Confidentiality and anonymity were also maintained and strictly protected. During an in-depth interview, participants were free to drain their feelings, and they 
http://wjst.wu.ac.th

were comfortable to talk about their feelings and traumatic experiences. Moreover, more information for further support as they needed was provided at the end of interview. None had developed emotion distress or withdrew from this study.

\section{Data collection}

Data were collected through the in-depth interviews, using an interview guide to explore the strategies that widows used to heal themselves after loss of spouse. Observations of the non-verbal behaviors during interview and field notes were written during data collection and analysis. Participants were initially asked 4 main questions, starting with 1) please tell me about your current situation, or recent feelings, in order to make sure participants were ready to heal themselves and did not any psychological distortions; 2) please explain your responses and your feelings in the earlier stage after loss of your spouse until the present time; 3 ) and how did you deal with, or how did you find the ways or strategies you used to deal with, your suffering and overcome it, and 4) give details of ways in which Buddhist beliefs influenced your way of life and allowed you to heal yourself? Furthermore, probing questions were used to clarify queries related to participants' responses or unclear context, and subsequent or contrasted questions were also used; for example, when participants talked about their loss or suffering from their loss, the researcher asked for further detail, such as; "How did you do to overcome your suffering (KhwamMai-Sa-Bai-Jai), then what or whom did you learn from"

The interviews were mostly conducted at participants' home at convenient times. The interviewing time was for between at least 60 and $90 \mathrm{~min}$, with audio recordings used. Five participants were interviewed at least twice until data saturation was gained.

\section{Trustworthiness}

To ensure and enhance the rigor of this study, the following procedures, as proposed by Lincoln and Guba [35], were performed. These included peer debriefing among the researchers to enhance the credibility of the data collection and analysis. Information was checked and validated by the team, and the participant checked and confirmed the information after it was transcribed from the audio recorder.

Moreover, confirmability was employed by in-depth interview and observation of behavior during the interview and records in the field notes. Furthermore, the researcher checked and traced back to the content and information to strengthen the findings. Prolonged engagement with the participants, to gain better understanding of the backgrounds and contexts, was conducted by interviewing each participant for 60 to $90 \mathrm{~min}$ (between 2 and 3 times). The verbatim transcriptions of the audio records were kept for an audit trail.

\section{Data analysis}

The transcriptions were read and analyzed by means of content analysis. The data were coded, categorized, and interpreted, and finally main themes were identified [32,34]. Firstly, the researcher coded the important keywords that represented the strategies used by widows. Constant comparison was used during the data analysis procedure, in order to formulate the main themes. Member checking (by participants) was also used during the data collection, and the process of data analysis was intensively advised on by the supervisor, who had expertise in qualitative study. Finally, 3 main themes were generated to explain the strategies that Thai Buddhist widows used to heal their suffering after the sudden loss of spouse by terrorist attacks in southernmost Thailand.

\section{Results}

The data derived from 5 Buddhist widows were used to describe the widows' backgrounds, perceptions of suffering, and the healing strategies that widows used to heal themselves. The finding from primary analysis is as follows. 


\section{Demographic characteristics of participants}

The 5 participants selected for this study were Buddhist, aged between 37 and 64 years, and lived in different districts of Pattani province, in the south of Thailand. They had experienced the sudden loss of their spouses within the last 2 to 10 years. Regarding their educational backgrounds, 3 widows completed primary school, and 2 secondary school. They had different occupations and, after the loss of a spouse, some widows had changed these occupations. One of the widows moved from being a housewife to a family leader; another 2 changed from being grocery store owners to employees of private companies; one widow moved from being a housewife to being an owner of housing for rent, in order to gain her income, and another worked as a volunteer to help other widows. In addition, a few received support from government sources, i.e., they were given either compensation for the family leader death (about 12,200 US) and received $140 \mathrm{US} /$ month for volunteer work at a remedy center. One widow, who had no other income to support her, complained that it was inadequate to cover all household expenses. Three widows had 2 or 3 children living with them, while 2 others had no children, and one of those 3 widows took care of her own family (her parents).

\section{Widows' experiences of suffering}

The 5 Thai Buddhist widows described similar feelings of their suffering after the sudden loss of spouse from terrorist activities in the unrest areas. Feelings of shock, grief, numbness, denial, and anger were expressed among the Buddhist widows between 2 weeks and 2 months after the incident. During this time, they did not realize themselves how it was going to be; they just thought about how and why it happened to them. In addition, they expressed their needs for a private life space from others, except from their own family and closest friends (who often visited). Lastly, the participants explained that, when time passed, they realized and were concerned with their life with their living family members. Two participants stated that they were afraid of a future life without their husbands' support. They sometimes were confused and felt guilty frequently as they asked questions; "Why did my husband die, and not me?" (Id. 02) or "Why did the loss come to me?" (Id. 02), and "How will I do or can survive without my husband?" (Id. 05).

Suffering also continued throughout the stage of denial of the loved one's death. They were angry at the people who killed their husband. As one widow reflected;

"Why did they shoot him?" "They were very bad people... he was a murderer, 'murderous cruelty'... I hate the one who killed him" (Id. 02).

Moreover, she reflected on her suffering that "I felt like my heart was breaking... It was painful, and many questions came up in my mind in those days. How could I live? How could I go to work? Who would take me to the doctor if I got sick?" (Id.02).

Furthermore, another widow explained her guilt as she asked her husband to drive her to the workplace, and this caused him to be killed. She still had evidence of much emotional tension and reflection on her suffering when she told her story. Overall, every participant's suffering lasted at least 6 months, depending on the strategies the individual used for healing.

\section{Strategies for healing}

Eventually, 3 themes emerged, reflecting the strategies that widows used to heal their suffering, which consisted of 1) making merit under the Buddhist belief, 2) venting their feelings and emotions with family and close friends, 3) setting a new life by deep understanding of Dukkha (suffering) and the natural law of life, which are the most important aspects of Buddhism, as previously discussed.

\section{Making merit under the Buddhist belief}

As per Buddhist belief and practices, 'Merit making' was performed. The Thai Buddhist traditional believe that 'Merit making', such as praying, which is the most common practice, followed by practicing meditation, and offering money and food to monks and poor people, are the best good deeds, because they need to do a good deed for the loved one who passed away and the many who survived; thus 'Merit making' was often performed among the 5 Buddhist widows after the deaths of their spouses. Under this 
http://wjst.wu.ac.th

religious practice, the Buddhist widows tried to seek ways to heal themselves by making merit when they felt much sorrow and suffering about their husbands' deaths. They believed that making merit could help their husbands gain happiness and live in a good place.

The widows reflected that they needed time to make themselves accept the death of their husbands. Due to the unacceptable deaths, most of the widows spent much time, between 2 weeks and 6 months, to accept their husbands' deaths. Under the Buddhist belief, making merit helps the widows to have a chance to rethink, compensate, and look for a new life, in order to reduce their suffering. Those who accepted death realized that suffering may affect their health, and that everyone needs to overcome the worst experiences or crisis situations. As one widow said;

"I was afraid of the suffering and needed to end the suffering as soon as possible" (Id. 01). (Id. 02).

Furthermore, another one said "If I still hold on to suffering, it would affect my health conditions",

Two participants compensated themselves by being ordained as nuns. They reflected on their beliefs that being a nun helped them to have more time to perform the whole of merit making, such as praying, practicing meditation, and learning the Buddha's teaching, and gain the best merit for their husband and release their own suffering. Although being a nun cannot reduce all suffering, it was regarded as a spiritual support for healing themselves. Furthermore, 3 participants described that praying as usual practice in daily life was effective in lessening their suffering and to enhance their mind; as one widow said, "Praying could enhance me to engage in a peaceful mind and reduce my suffering" (Id. 01). Another widow gave a similar response when she said;

"I always pray for my husband to be in the good place (or heaven in the Thai cultural belief) and I was also praying when I was suffering or worrying in my life, I also hoped that praying could help my husband's spirit to live in a good place" (Id. 02).

\section{Venting with family's members and closest friends}

Venting their feeling with family members and close friends (who they trusted) was a strategy that the widows used to drain their uncomfortableness and their emotions with each other; talking to the husband's picture when they felt loneliness was another strategy. They described that talking or venting to others help them lessen their depression. All participants reflected their feeling of loneliness in the earlier stage, since they were not prepared for the sudden loss of their husband, and they were also afraid of many others dying by terrorist attacks in the unrest situation area. A few of them initially preferred to separate themselves from others and needed a private life to be with the loved one, including preparing themselves for moving on, before seeking support from others. However, a few widows stated that their family and closest friends played an important role in the period to facilitate feelings of loneliness during the time of suffering. As one widow said;

“...My family always assists me to overcome my loneliness, my suffering, they facilitate me to give up and move on for the good future, and they also support me in everything..." (Id. 02).

Moreover, talking with friends and family members, such as a mother, father, or their child, was helpful in reducing their stress and suffering. Family and closest friends not only supported their emotional responses with sympathy, but also learned to accept their suffering. They would follow the Buddha's teaching and thinking, that suffering is one of the natural laws. Venting to each other also helped them to realize the truth of dying and lessen suffering. As one widow said;

"At the moment, I needed to drain my feelings, such as anxiety and fear, and I needed someone to listen to me....sometime my friends asked me about some Buddhist proverb which taught me more understand of death" (Id.02).

Another participant used this strategy to maintain a relationship with her husband who passed away by talking to his picture. It not only released her loneliness, but also allowed her to keep the good feeling that her husband was still alive and was with her at all time. As one widow said;

"I tell him everything in my daily life, I needed him to know that I'm fine, and not to worry about me” (Id. 02). 
http://wjst.wu.ac.th

Another widow who left her husband's picture on dining table reflected that she was able to talk to him during eating and, similar to the previous participant, she said;

"I talk with his spirit every day before going to sleep, and I tell him not to worry about me, I sound good.... If my husband's spirit was not worried about me and our children, my husband's spirit would go to the heaven by this way" (Id. 05).

In addition, the assistance from families and close friends played a vital role in their healing strategies at this stage, as reflected by experiences from 2 participants. One, who had no children, said;

"My closest friends that I trusted gave me much support; when I felt lonely, or was suffering, I always called her, and every time she helped me to lessen my emotions. Because she was welcome to listen to my emotions until I felt relief and comfortable, I love her very much" (Id. 05).

Another participant described her worry that the situation would affect others in the family, as she said ;

"If I still have deep suffering, it may affect my family's life, who are worried about me, and may lead my family members, such as my mother, father, and my children, to suffer as well as making my husband's spirit worried about me" (Id. 03).

This may help them rethink about a new life, look ahead for support, and try their best to do good things for themselves and for their husbands' spirits.

Setting a new life after understanding the natural law of life

The data revealed that the depth of understanding of 'Dukkha' (suffering) and 'the natural law of life' in Buddhism enhances most widows to be grown-up and think in a positive way. One participant created a mindset of a new life after she understood Dukkha and sought the right way to lessen her suffering by working as a volunteer to help other widows. She stated that she gained better understanding of the national law of human life from Buddha's teaching. As she said;

"...Exposure to the loss of a husband made me understand the natural law that Buddhism teaches more, and underwent positive thought; after I worked as a volunteer in a District Remedy Center... I realized that many were in difficult situations, not only me. It pushed me to move to for a new life goal... (Id. 01).

Furthermore, another widow also used merit making to heal and enhance her mind to understand facts from Buddhist teachings, as she said;

“... Making merit (praying, offering food or money for monks and donations for many who are in difficulty) was not only beneficial for my mind, but also it may help my husband's spirit to be in a good place. Furthermore, I believe that making merit should help me to be in a good place in the next world... The Buddhist belief was much involved in my healing strategies, such as "Dukkha depends on what we do, and everyone can lessen the suffering by themselves". Making merit by offering food to monks made me gain more happiness, and it also lessened my Dukkha (Suffering/Khwam Mai-Sa-Bai-Jai).... When I made merit many times, the suffering or Dukkha disappeared from my mind.... Meditation practicing is another good thing that I have done. I believe that it influenced my life as it increased happiness in my mind, so that I tried to overcome the suffering by myself for a good future" (Id. 02).

Another widow reflected about the benefit of Buddhist practice and her successful healing in addition to the psychological change, and had a new set of future plans, as she said;

"...I agree with them, and I think if I still have deep sorrow, my husband cannot go to a good place, and his spirit may be worried about me... I felt comfortable and was happy (Sa-bai-jai) when I was ordained as a nun, and I think it was the best thing that I could do for my husband and my daughter's spirits.... From my view, praying make me engage in a peaceful mind and calm from suffering or any emotion,...I realized that the crisis from the sudden loss of my husband enhanced me to be a stronger person, and I'm so proud of myself, nowadays....(Id. 03).

This is regarded as one of the Natural Laws of Life in Buddhist teaching. Moreover, seeing others' loss would not only teach them about the natural law of Dukkha (suffering), but also enhance the healing in their mind and be stronger. As one widow reflected on her situation, and how it changed her mind, compared with the time before her husband passed away, she said: 
http://wjst.wu.ac.th

"... When I worked a volunteer for the remedy project, I saw many widows, both Buddhist and Muslim, that had much more difficulty than me. It made me understand that everyone should be exposed to loss and suffering, not only me, so that I tried to continue good deeds to lessen my emotion..." (Id. 01).

Most participants described more about their strategies related to the Buddhist belief since they had accepted the reality of their husbands' deaths, living with their children, and taking full responsibility for household tasks. This was related to the Buddhist belief of understanding in the "Natural law of Life" and could guide them to seek a better life. For example, they used the natural law for explaining the link of past, present, and next life, as one widow said;

"My husband's dying follows the natural law of life" and "his dying depended on his past deeds or his old karma" (Id. 02).

However, all of the strategies they performed were combined together, i.e., making merit for the husband would benefit his next life, and working as a volunteer to help other new widows. They found that it was more beneficial for their health and healing, including enhancing their positive psychological health. As one widow reflected;

"Recently, I thought I am stronger compared to the time when my husband was alive; I can support others who lacked opportunity and are faced with difficulties..." (Id. 01).

Not only psychological health has been changed, but also the widows' social lives, which has enabled them to set a new priority for their lives. As one of them said;

"I have much positive thinking and a peaceful mind by making merit and performing my good deeds; it also includes my forgiveness to people who took my husband's life away from me" (Id. 01).

\section{Discussion}

The findings revealed that widows had similar experiences after the loss of their husbands from terrorist attacks, and it took time to heal themselves. Time had allowed them rethink and realize their crisis situations. This is usually regarded as a normal grief response which occurs after the loss of a loved one or the experience of a crisis event in many people [2,3]. Moreover, the sudden loss of a beloved one among widows and widowers makes them incapable of even performing basic activities, and most of them appear senseless to plan for the future [36].

In this study, 3 main strategies to relieve suffering were dominant compared to previous studies [31], although they were similar in the simultaneous reaction to the sudden loss of a beloved one. Additionally, Thai Buddhist culture had more influence in helping Buddhist widows to overcome their suffering by practicing more 'Merit Making,' praying, and meditation practicing, so that they believed that making merit helped them to get a better understanding of the death and acceptance of the husband's death.

Buddhist teaching played an important role in the widow's healing strategies, including making merit for a loved one who passed away both during and after the funeral ceremony. Buddhist widows also believed like other Thais regarding birth and rebirth, that making merit could help the husband's spirit to be reborn in a good place or in heaven [37]. Moreover, widows believed that making merit could improve their spiritual well-being, decrease suffering emotions, and compensate their loss. Several actions of merit making were performed to relieve their suffering, such as a praying, meditation practice, and learning Dhamma. Listening to Dhamma from a monk is another common practice of making merit in Buddhism, which helps people learn about content directly related to the main aim of Buddhism, i.e., concerning suffering (Dukkha) and the ways that lead to the end of suffering. Eventually, making merit for a long time could help to or to completely relieve widows' suffering by promoting the sense of forgiveness in a widow's mind; as one participant described, "the longer time of merit making I had, the anger and fear of terrorist attacks disappeared from my mind". Forgiveness is regarded as a great giving of life, which refers to freedom from suffering by letting go of things that make them stressed or angry. Furthermore, Buddhist teaching (Dhamma) enhances the widows' understanding that death is a natural law, and each person will walk to the end of time one day. Thus, making merit and following Buddhist doctrines often provides ways to achieve spiritual growth [23]. 
http://wjst.wu.ac.th

Another strategy that widows used to heal their suffering was ventilating their feelings and emotions with family and close friends. This usually comprised the widow's parents, her children, and her closest friends, all of whom she trusted. Moreover, talking to their husbands' pictures or belongings, such as personal items, and the husbands' ashes, enhanced widows in the relief of their loneliness due to the permanent absent of her husband, thereby easing suffering. This finding was consistent with prior research [22] regarding adequate social support helping Buddhist mothers to heal themselves, by talking with their husbands or closest friends. A significant person in social support has been a strong influencing factor in decreasing functional impairment in patients with depression and in increasing the likelihood of recovery [38]. In this study, continuing support and the interaction of widows with their family and others over a period of time could assist them to be able to change their attitude to future life, instead of living with loss. In addition, venting their feelings seems to be helpful as a self-reflection while keeping quiet. In this study, it was a way for women to examine their emotions and how to improve themselves.

In addition, it is clear that understanding Dukkha (suffering) and the natural law of life could help widows learn to have new lives and plan for their future lives. Making merit and praying not only reduced their suffering, but also improved their understanding of the human life cycle. Moreover, Buddhist teaching helped them to have positive thinking, and engaged themselves in a positive way of life, eventually paving the way for the development of forgiveness to those people who killed their spouses, and reduced fear in their minds, in order to survive the rest of their lives. Finally, negative feelings, such as suffering (Dukkha), loneliness, and hopelessness, slowly faded out from their minds as a part of regular practice in the Buddhist way of life. This result was congruent with a prior study [16] that noted the role of Buddhism in the adaptation to widowhood in Sri Lanka's widows. It was stated that adaption to widowhood in Sri Lanka started with the Buddhist religious funeral rites being performed, where during the funeral ceremony the Buddhist monks usually taught them about life and death or the journey of the cycle of 'samsara' or a cycle of re-birth, thereby gaining understanding of death and dying. Then, the more widows gained understanding of the life cycle, and a greater reduction of their grief and suffering. In addition, most widows explained that Buddhist practices, such as praying and meditation training, enhanced them in gaining an understanding of the human life cycle in terms of 'natural law' which was guided by Buddha's teaching [23,39]. This could then relieve widows' suffering or human suffering.

Most of the widows recovered to normal life following their self-healing strategies with support from family, friends, and health care professionals. Furthermore, it is necessary to understand the dynamics of suffering and healing methods among widows, which may need to be developed and provided as individual needs.

\section{Conclusion and recommendations}

The study findings provided important knowledge which was derived from the Buddhist widows, who experienced suffering from the sudden loss of a spouse during the unrest situations in the southernmost provinces of Thailand. The strategies used by Thai Buddhist widows could be of benefit to guide nursing practice to provide appropriate support and assist new widows and Thai women who face much suffering to heal themselves by following Buddhist practice. Health care providers should be supported in their efforts to promote the mental health of the widows and enhance post-traumatic growth at each stage of the loss after exposure to traumatic events.

It is suggested that the initial approach in the healing process requires family members or close friends, who are trusted, including the health care team, who are able to support those who experience devastating loss and suffering, as the widows reflected that they need to express their feelings and appreciated being listened to in the initial period of the loss. Multiple approaches with significant persons are able to lessen the widows' suffering and promote post-traumatic growth. Further study should include different backgrounds of widows, such as Muslim widows, or be conducted with male survivors, and examine the process using grounded theory to generate a healing model based on the widows' experiences. 


\section{Limitations}

The knowledge gained from 5 Thai Buddhist widows' voices has limitations that need to be considered when applying the findings. It was conducted only on those who work particularly in the unrest area and concerned only Buddhist widows.

\section{Acknowledgements}

I would like to express my sincere thanks to all widows for their invaluable time in sharing their experiences and in their participation in this study. I also thank the partial funding supported by the Graduate Studies and Research Center for the Caring and Healing of People with Trauma, Emergency and Disaster, Prince of Songkla University.

\section{References}

[1] NA Gasseer, E Dresden and GB Keeney. Status of women and infants in complex humanitarian emergencies. J. Midwifery Women Health 2004; 49, 7-13.

[2] E Kübler-Ross. On Death and Dying: What the Dying have to Teach Doctors, Nurses, Clergy and Their own Families. Routledge, New York, 2009.

[3] C Young and C Koopsen. Spirituality, Health, and Healing: An Integrative Approach. $2^{\text {nd }}$ eds. Jones and Bartlett Publisher, Canada, 2011.

[4] S Schaal, N Jacob, JP Disingizemungu and T Elbert. Rate and risk for prolong grief disorder in a sample of orphaned and widows genocide survivors. BMC Psychiat. 2010; 10, 55.

[5] DG Kilpatrick, HS Resnick, MS Milanak, MW Miller, KM Keyes and MJ Friedman. National estimates of exposure to traumatic events and PTSD prevalence using DSM-IV and DSM-5 criteria. $J$. Trauma. Stress 2013; 26, 537-47.

[6] PN Santiago, RJ Ursano, CL Gray, RS Pynoos, D Spiegel, R Lewis-Fernandez, MJ Friedman and CS Fullerton. A systematic review of PTSD prevalence and trajectories in DSM-5 defined trauma exposed populations: Intentional and non-intentional traumatic events. PLoS One 2013; 8, e59236.

[7] S Panphet and A Ramansiriwong. Violence situation in lower south of Thailand affected 2,295 widowers, and 4,455 orphans (in Thai). Available at: http://www.isranews.org/south-news/stathistory/item/3204, accessed January 2017.

[8] V Poozu. To stop the violence in southernmost; 6,000 widows and 2,800 orphans (in Thai). Available at: www.isranews.org/south-news/academic-arena/item/34676-orphan_34676.html, accessed January 2017.

[9] W Paonil and L Sringernyuang. Buddhist perspectives on health and healing. Chulalongkorn J. Buddhist Stud. 2002; 1, 93-105.

[10] V Jaeuabong. Behind the curtain of the unrest situation with remedies widows and orphans. Available at: http://www.dmh.go.th/abstract/details.asp?id=4611, accessed January 2017.

[11] U Hatthakit and P Thaniwathananon. The suffering experiences of Buddhist tsunami survivors. Int. J. Human Caring 2007; 11, 59-66.

[12] ES Idemudia, JK William, KK Boehnke and G Wyatt. Gender differences in trauma and posttraumatic stress symptoms among displaced Zimbabweans in South Africa. J. Trauma. Stress Disord. Treat. 2014; 2, 1340-54.

[13] I Sever, E Somer, A Ruvio and E Soref. Gender, distress, and coping in response to terrorism. $J$. Women Social Work 2008; 23, 156-66.

[14] P Punnara. 2006, Stress and Coping of Widows Losing their Husband from the Situation of Unrest in Three Southern Border Provinces: A Case Study at Rotanbatu Center, Narathiwat Province. Master Degree, Prince of Songkla University, Thailand.

[15] NZ Somhlaba and JW Wait. Stress, coping styles, and spousal bereavement: Exploring patterns of grieving among black widowed spouses in rural South Africa. J. Loss Trauma. 2009; 14, 196-210. 
http://wjst.wu.ac.th

[16] A Edirisinghe and D Wijesinghe. Role of Buddhism in the adaptation to the widowhood caused by the ethnic conflict in Sri Lanka. Available at: http://www.undv.orgpanel2/11WijisingheFINAL.pdf, accessed January 2017.

[17] AL Holm and E Severinsson. Systematic review of the emotional state and self-management of widows. Nurs. Health Sci. 2012; 14, 109-20.

[18] SH Stige, PE Binder, JH Rosenvinge and B Traeen. Stories from the road of recovery: How adult female survivors of childhood trauma experience ways to positive change. Nordic Psychol. 2013; 65, 3-18.

[19] AM Mays. 2010, To Suffer in Silence: Confederate Widows' Grieving Processes after the Civil War. Dissertations and Theses, University of North Carolina, Chapel Hill, USA.

[20] CL Park. Religious as a meaning-making framework in coping with life stress. J. Soc. Issues 2005; 61, 707-29.

[21] G Prati and L Pietrantonia. Optimism, social support, and coping strategies as factors contributing to post-traumatic growth: A meta-analysis. J. Loss Trauma Int. Perspect. Stress Coping 2009; 14, 36488.

[22] K Wiriya, U Hatthakit, W Wiroonpanich and L Smith-Battle. Buddhist mothers' experiences of suffering and healing after the accidental death of a child. Thai J. Nurs. Res. 2009; 13, 227-41.

[23] P Payutto. Buddhadhamma. Natural Laws and Values for Life. State University of New York, New York, 1995.

[24] B Bodhi. The Noble Eightfold Path: Way to End of Suffering. Available at: https://store.pariyatti.org/Noble-Eightfold-Path-The--PDF-eBook_p_4795.html, accessed January 2017.

[25] KS Dhammananda. What Buddhists Believe. $4^{\text {th }}$ ed. Buddhist Missionary Society, Malaysia, 1987.

[26] C Srichannil. Buddhist psychology: The way to heal suffering and cultivate personal mental health. Univ. Thai Chamber Commerce J. Human. Soc. Sci. 2009; 29, 188-208.

[27] L Davis and S Kurzban. Mindfulness-Based treatment for people with severe mental Illness: A literature review. Am. J. Psychiat. Rehabil. 2012; 15, 202-32.

[28] S Schmidt. Mindfulness and healing intention: Concept, practice, and research evaluations. $J$. Alternat. Compl. Med. 2004; 10, S7-S14.

[29] RP Zahourek. Healing: Through the lens of intentionality. Holist. Nurs. Prac. 2012; 26, 6-21.

[30] W Prohmpetch and PA Songwathana. 2014. Literature review of psychological healing in people affected by terrorism in southern Thailand. Hatyai, Songkla, Thailand.

[31] P Songwathana, K Baltip, W Prompet and S Wichaidit. Healing experiences of women losing the family's members from the unrest situations in southernmost of Thailand (in Thai). Thai J. Nurs. Council 2017; 32, 55-66.

[32] M Sandelowski. What's in a name? Qualitative description revisited. Res. Nurs. Health 2010; 33, 77-84.

[33] MA Neergaard, F Olesen, RS Andersen and J Sondergaard. Qualitative description the poor cousin of health research. BMC Med. Res. Methodol. 2009; 9, 52

[34] AV Lambert and CE Lambert. Qualitative descriptive research: An acceptable design. Pac. Rim Int. J. Nurs. Res. 2012; 16, 255-6.

[35] YS Lincoln and EG Guba. Naturalistic Inquiry. Sage Publications, Beverly Hills, CA, 1985.

[36] S Goodrum. The interaction between thoughts and emotions following the news of beloved one's murder. Omega J. Death Dying 2005; 51, 143-60.

[37] S J Laumakis. An Introduction to Buddhist Philosophy. Cambridge University Press, United of America, 2008.

[38] F Ozbay, DC Johnson, E Dimoulas, CA Morgan, D Charney and S Southwick. Social support and resilience to stress: From neurobiology to clinical practice. Psychiatry 2007; 4, 35-40.

[39] P Harvey. An Introduction to Buddhism: Teachings, History and Practice. $2^{\text {nd }}$ eds. Cambridge University Press, USA, 2013. 